\title{
Social Amenities and Academic Performance in Primary Schools in Gichugu Constituency, Kenya
}

\author{
Priscah Wanjiku Githaka ${ }^{1}$, Michael W. Gachahi ${ }^{1 *}$, John Mwaruvie ${ }^{1}$ \\ 1 School of Education and Social Sciences, Karatina University, KENYA
}

*Corresponding Author: mgachahi10@gmail.com

Citation: Githaka, P. W., Gachahi, M. W. and Mwaruvie, J. (2019). Social Amenities and Academic Performance in Primary Schools in Gichugu Constituency, Kenya. European Journal of STEM Education, 4(1), 04. https://doi.org/10.20897/ejsteme/3948

Published: April 29, 2019

\begin{abstract}
Social amenities in primary schools play an important role in the provision of quality education. Social amenities include play materials and sanitation facilities. This study aimed at examining the impact of social amenities on academic performance in primary schools in Gichugu Constituency, Kenya. The objectives of this study were to assess the status of social amenities, to establish how sanitation amenities influence pupils' performance and lastly, to evaluate challenges facing provision of social amenities in primary schools in Gichugu Constituency, Kenya. This study was guided by Social Constructionist Theory. The study adopted the descriptive survey research design. The target population consisted of 75 primary school head teachers. Kathuri and Pal's Table for Sample Size Determination was used to arrive at a sample size of 63 school head teachers who were randomly selected from the target population. A questionnaire and an observation guide were used to collect data from the respondents. Data was analyzed using descriptive statistics with the aid of Statistical Package for Social Sciences (SPSS Version 20). The study established that in majority of the primary schools, pupils had access to clean and safe drinking water though pupils in some schools used water from nearby rivers and stream. The study also found out that majority of the schools had adequate sanitation amenities. However, the study established that sanitation facilities did not cater for learners with physical disabilities. The study established that social amenities influenced learners' academic performance in primary schools. Further, the study established that financial challenges affected provision and maintenance of social amenities in primary schools in the study region. The study recommended that the Ministry of Education and other education stakeholders should facilitate the provision and maintenance of social amenities in primary schools in Kenya in order to improve pupils' academic performance.
\end{abstract}

Keywords: social amenities, sanitation, academic performance, play materials

\section{INTRODUCTION}

One of the Millennium Development Goals calls on countries to reduce the proportion of people without access to basic sanitation by half (Guy and Haller, 2007). Williams et al. (2008) noted that eradication of open defecation, improved hand washing practices as well as ensuring that liquid and solid wastes are properly managed would not only help in ensuring proper sanitation practices but also save an estimated 1.9 billion school days that could be lost due to diarrhea illness and other water and sanitation-related diseases. It is important to note that schools are important and stimulating learning environments for children that have the potential to significantly alter the behaviour patterns of students leading to improved sanitation practices. 
Social play amenities also include play materials which allow social development of children within the school and at home. Social play materials play an integral part in allowing children develop communication, persistence and other social skills necessary for development of language, motor skills as well as intellectual growth (Edwards, 2006). In a study conducted in American schools on the role of athletics and academic performance, Gorman (2010) studied how provision of play amenities influences growth and development of intellectual capacity of children. Gorman noted that there are children whose motivation in play influenced their intellectual development. Lack of these materials reduces their level of motivation and eventually results in poor intellectual development. This study disputed earlier findings of McMillen (1991) who had argued that athletics eligibility did not have any positive relationship with academic performance. The study also disputed Beem (2006) who noted that pressure to produce winning teams gave rise to lower academic performance among the top performers in schools. However, Gorman (2010) noted under school sponsorship programmess, the participants were more inclined to post positive academic achievements to be sustained in the schools. The current study excludes school sponsorships based on one's play prowess and therefore will be different from that of Gorman (2010). Gorman's study was based on senior school learners who were also highly involved in athletics and therefore the findings involved learners who were at advanced stages in their formative years unlike the current study that is exclusively on primary school children.

Owoeye and Yara (2011) conducted a study in Ekiti State, Nigeria to determine how social amenities in school contribute to academic performance of learners in schools. Using descriptive survey design of the ex-post factor type, the study determined that school social amenities whether health, sanitation, play amenities and academic oriented amenities all have an effect on academic performance. The study therefore argued that provision of academic and social amenities was paramount if the community were to have higher expectations in academics. The findings in this study corroborated the findings of Owoeye and Yara (2011) who argued that social amenities affected children's cognitive development and therefore directly influenced their academic performance. Nigeria is a relatively rich African country due to oil presence and therefore the status of the social amenities in these schools and the level of incomes of the parents among other factors could have influenced the results of the studies. Though Kenya is a developing country, the status of her primary schools may not match that of the Nigerian schools.

Gabbad and Elawad (2014) carried out a study covering around 500 primary schools in Sudan. This study found out that there was a significant relationship between access to potable water and intestinal parasite infection among primary school children. The study noted that the distribution of these infections was mainly associated with poor personal hygiene, environmental sanitation and limited access to clean water among pupils in primary schools in Elengaz region. In this study, Gabbad and Elawad concluded that the spread of intestinal parasitic infections in a population is generally associated with water supply and sanitation besides other factors. This study argued that diseases affected the grades that children achieved in their examinations and to a large extent affected their education progression.

Redhouse (2004) carried out a study in Tanzanian schools to determine the rate of access to safe drinking water. In this study, a sample of public schools was selected and was intended to determine how many school children had access to safe drinking water at a distance of 15 minutes away from the school. This study concluded that less than $12 \%$ of the public primary schools had access to safe drinking water. The study noted that lack of safe piped water contributed to prevalence of diseases associated with unsafe water such as typhoid and cholera. The study noted that such sicknesses contributed to lower academic achievement among children due to absenteeism and slow cognitive development due to illnesses. Kirinyaga is served by rivers emanating from Mt Kenya and thus the level of impurities and pollution in these rivers is low.

Milkie and Warner (2011) argued that schools should ensure that they have ample play amenities, access to play tools and teachers should be encouraged to participate in play activities together with learners. The authors argued that schools that lacked play amenities were unsuitable for learning particularly to early age learners. In order for learners to develop motor skills which are applied later in life, schools should provide a variety of amenities such as horizontal trunks, ropes and other play items that provide learners with a variety of play amenities which broaden their play scope. Lawrence (2011) argued that innovation in schools can increase involvement of learners during play. He found out that movement increases children's physical and cognitive abilities. It is through activities such as role play, seat changing, coordinated dances among others assist learners to get basic skills such as timing, coordination and concentration. These skills are very useful in the development of language and problem solving skills which can ultimately lead to improved academic performance.

In Kenya, Eshuchi (2013) carried out a survey of various campaigns in schools to improve the hygiene standards such as the WASH Campaigns. Eshuchi noted that the government and non-government stakeholders in Kenya have initiated hygiene promotion campaigns in public primary schools across the country. He noted that this includes curriculum developed by the Ministry of Public Health and Sanitation (MoPHS), the Ministry of Education (MoE), the Kenya Institute of Curriculum Development (KICD) together with other stakeholders 
sensitizing the public on hygiene and sanitation. Dettol Hand Washing campaign is one of the strategies used to sensitize children on the need to wash hands. Mbula (2014) carried out a survey of sanitation amenities in schools in Machakos County, Kenya. Mbula noted that improved sanitation amenities are not limited to provision of latrines and water but also to the fact that these amenities should be well ventilated and should have slab floors. Mbula established a relationship between good social amenities and improvement in school attendance as well as overall performance of pupils in examinations.

\section{STATEMENT OF THE PROBLEM}

Availability and maintenance of social amenities in learning institutions cannot be ignored. Public primary schools in Kenya face financial challenges which affect provision, maintenance and expansion of social amenities to cater for the increasing number of pupils occasioned by the introduction of free primary education in Kenya in 2003. It is therefore important that a study should be undertaken to assess the status of social amenities in primary schools in Kenya. Secondly, studies on the impact of social amenities on academic performance have not been exhaustive. Most of the studies in this area have been carried out in more developed countries whose conditions may not match the Kenyan context. The current study sought to establish the impact of social amenities on academic performance in primary schools in Gichugu Constituency, Kenya.

\section{OBJECTIVES OF THE STUDY}

The following were the specific objectives of the study:

i. To assess the status of social amenities in primary schools in Gichugu Constituency, Kenya.

ii. To establish how sanitation amenities influence pupils' performance in primary schools in Gichugu Constituency, Kenya.

iii. To evaluate challenges facing provision of social amenities in primary schools in Gichugu Constituency, Kenya

\section{THEORETICAL FRAMEWORK}

The study was guided by the Social Constructionist Theory as explained by Sahlin (2006). This theory posits that knowledge acquisition involves the following facets; language used, the surrounding community, social interaction and other cognitive functions which influence learners' intellectual development. This study is of the view that learners' knowledge acquisition is influenced by social engagements and that social amenities play a major role in the intellectual development of children. The provision of social amenities in schools assists learners in the development of social and intellectual skills which ultimately promote development of life skills which enable learners to cope with challenges in life. .Social play materials provide learners with tools to exercise and develop their social skills. Social skills ensure learners are capable of interacting with other learners, the community and the society at large. Social processes therefore play a pivotal role in the development of intellectual thought and thus provision of social amenities could influence learners' academic performance.

\section{RESEARCH DESIGN}

This study adopted the descriptive survey research design. According to Mugenda and Mugenda (2003), descriptive survey research design enables researchers to get information about a phenomenon under study from selected respondents. The target population was 75 primary school head teachers from Gichugu Constituency, Kenya. Kathuri and Pal's Table for Sample Size Determination was used to arrive at 63 head teachers who were randomly selected from the study region. The data collection instruments used in this study were questionnaires for headteachers and an observation guide. The headteachers' questionnaires contained open ended and closed ended questions which were directed towards collecting data on social amenities and academic performance in primary schools in Gichugu Constituency, Kenya.

\section{FINDINGS}

The study sought to establish the status of social amenities in primary schools in Gichugu Constituency, Kenya. Information on status of social amenities in primary schools in this region was sought from the headteachers. 


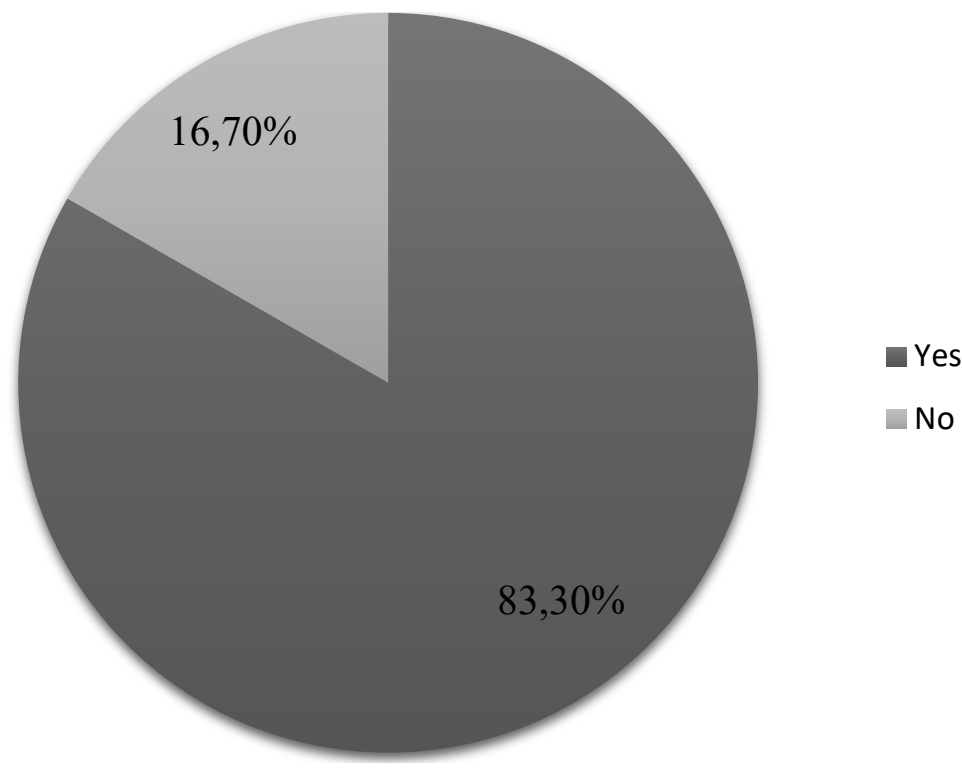

Figure 1. Status of Social Amenities in Primary Schools

Table 1. Adequacy of Sanitation Amenities

\begin{tabular}{lcc}
\hline Average School Population & Ratio of Pupils to Toilets & Average Mean Grade (2014 KCPE) \\
\hline $200-250$ & $1: 25$ & 240 \\
\hline & $1: 16$ & 290 \\
\hline $300-500$ & $1: 13$ & 327 \\
\hline $1: 50$ & 180 \\
\hline & $1: 33$ & 220 \\
\hline $1: 25$ & 250 \\
\hline $500-800$ & $1: 14$ & 325 \\
\hline $1: 27$ & 274 \\
\hline
\end{tabular}

Headteachers were asked to indicate the status of various social amenities in their schools. Figure 1 summarizes the status of social amenities in primary schools in the region with reference to water.

With reference to water, Figure 1 shows that majority of the head teachers (83.3\%) noted that their schools had access to clean safe drinking water. However, a considerable number of schools lacked safe clean drinking water $(16.7 \%)$. It was observed that in the $16.7 \%$ schools without safe drinking water, learners depended on water from streams surrounding the school as shown in Appendix 1 which shows learners fetching water from a stream. The water from streams is not treated and may expose learners to health hazards such as disease causing pathogens. The findings of this study agree with the findings of Mbula (2014) who found out that majority of the primary schools in Kenya had access to safe and clean drinking water partly due to the efforts of Non-Governmental Organizations that had undertaken WASH campaigns in rural areas of the country. Howver, the findings of this study contradict Obure (2009) who noted that public school pupils in Bondo District did not have access to safe drinking water and depended on river and dam water which they fetched on their way to school.

The respondents were asked to indicate if their schools had adequate sanitation amenities for their learners. The results are as summarized in Table 1.

Data in Table 1 show that majority of schools had inadequate sanitation amenities and this negatively affected their performance. There was evidence of an increased number of learner enrolment in schools with more sanitation facilities in the region due to better performance. However, the study observed that learners with physical disabilities shared the same sanitation facilities with others, thus learners with disabilities had difficulties using these facilities. The study also noted that in some schools, boys and girls shared the sanitation facilities. As shown in Table 1 above, schools with a favourable student sanitation ratio posted better results. The study concluded that schools with more sanitation facilities had better results in the KCPE. The study agrees with Maphoso and Mahlo (2014) who established that learners in schools that had the best health, sanitation and other social amenities posted better results in the examinations compared to learners in schools that had poor, worn out or no social amenities. This could be explained by cases of learner absenteeism, poor health among other resultant features associated to poor social amenities. 
European Journal of STEM Education, 2019, 4(1), 04

Table 2. Social Amenities and Language, Motor and Intellectual Growth

\begin{tabular}{lcc}
\hline Responses & Frequency & Percent \\
\hline Strongly Agree & 45 & $75.0 \%$ \\
\hline Agree & 15 & $25.0 \%$ \\
\hline Do not Know & 0 & $0.0 \%$ \\
\hline Disagree & 0 & $0.0 \%$ \\
\hline Strongly Disagree & 0 & $0.0 \%$ \\
\hline Total & $\mathbf{6 0}$ & $\mathbf{1 0 0 . 0} \%$ \\
\hline
\end{tabular}

Table 3. Diversity of Social Play Amenities and Children's Performance

\begin{tabular}{lcc}
\hline Responses & Frequency & Percent \\
\hline Strongly Agree & 36 & $60.0 \%$ \\
\hline Agree & 24 & $40.0 \%$ \\
\hline Do not know & 0 & $0.0 \%$ \\
\hline Disagree & 0 & $0.0 \%$ \\
\hline Strongly Disagree & 0 & $0.0 \%$ \\
\hline Total & $\mathbf{6 0}$ & $\mathbf{1 0 0 . 0} \%$ \\
\hline
\end{tabular}

Table 4. Academic Performance in Sampled Schools

\begin{tabular}{lccc}
\hline Year & $\mathbf{2 0 1 4}$ & $\mathbf{2 0 1 3}$ & $\mathbf{2 0 1 2}$ \\
\hline Average KCPE Marks Schools with piped water & Over 300 & Over 280 & $302-315$ \\
\hline Average KCPE Marks Schools without piped water & $240-280$ & $250-280$ & $236-280$ \\
\hline
\end{tabular}

Table 5. Poor Sanitation Amenities and School Absenteeism

\begin{tabular}{lcc}
\hline Responses & Frequency & Percent \\
\hline Strongly Agree & 32 & $53.3 \%$ \\
\hline Agree & 26 & $43.3 \%$ \\
\hline Disagree & 2 & $3.4 \%$ \\
\hline Strongly Disagree & 0 & $0.0 \%$ \\
\hline Total & $\mathbf{6 0}$ & $\mathbf{1 0 0 . 0} \%$ \\
\hline
\end{tabular}

\section{PLAY AMENITIES AND ACADEMIC PERFORMANCE}

The study sought to find out the influence of play amenities on academic performance in the region. Table 2 shows the results.

Data in Table 2 above shows that majority (100\%) of the school administrators agreed that play materials influenced learners' language development, psychomotor and intellectual growth. Play materials were observed to allow for development of persistence and other social skills necessary for the development of language, motor skills as well as intellectual growth. The researcher noted that swings, see-saws, football pitch and balls, merry-goround, slides among others were common in most schools. The study established that all the social play materials play an integral part in allowing children to develop communication, persistence and other social skills.

The respondents were asked if provision of diverse social play amenities influenced the children's motivation and interaction and the responses are summarized in Table 3.

Data showed that all $(100.0 \%)$ of the head teachers agreed that provision of diverse social play amenities influenced children's academic performance. The participants agreed that providing diverse social play materials motivates learners by providing a way for children to relax and indulge with others. The study noted that diversity of social play amenities influence children's academic performance.

The study sought to establish the relationship between sanitation amenities and academic performance of learners.

Data in Table 4 above shows that the average performance of the schools with piped water in the area under study was over 300 marks compared to schools without piped water which had average marks of 240-280. The study therefore showed that schools with piped water had higher test scores compared to those without water. The findings corroborate Owoeye and Yara (2011) who noted that social amenities affected children's cognitive development and therefore directly influenced their academic performance. The respondents were asked if sanitation amenities affected enrollment and the responses are summarized in Table 5.

Data in Table 5 showed that $96.6 \%$ of the head teachers agreed with the statement that poor sanitation amenities contributed to high incidences of absenteeism in schools. The data also showed that $3.4 \%$ of the head teachers disagreed with the statement. The study finds that poor sanitation amenities lead to an increase in the rate of absenteeism in schools. The findings concur with Gabbad and Elawad (2014) who noted that poor sanitation 
Table 6. Financial Constraints in provision of Social Amenities

\begin{tabular}{lcc}
\hline Responses & Frequency & Percent \\
\hline Strongly Agree & 47 & $78.3 \%$ \\
\hline Agree & 13 & $21.7 \%$ \\
\hline Do not know & 0 & $0.0 \%$ \\
\hline Disagree & 0 & $0.0 \%$ \\
\hline Strongly Disagree & 0 & $\mathbf{1 0 0 . 0} \%$ \\
\hline Total & $\mathbf{6 0}$ & \\
\hline
\end{tabular}

in schools led to high cases of diseases among the learners resulting in higher rates of school absenteeism. This absenteeism led to low academic performance since learners miss valuable learning time.

\section{CHALLENGES FACED BY PRIMARY SCHOOLS IN PROVISION OF SOCIAL AMENITIES}

The study sought to assess the challenges faced by primary schools in provision of social amenities to learners. The respondents were asked if financial constraints were a challenge in provision of social amenities in their schools and their responses are summarized in Table 6 . The study showed that all $(100.0 \%)$ of the head teachers agreed that financial constraints were a challenge in the provision of social amenities in public primary schools.

\section{CONCLUSIONS}

The study concluded that social amenities play a pivotal role in development of communication, intellectual and physical growth among learners in primary schools. The study further noted that lack of essential social amenities such as access to clean, safe drinking water and lack of adequate sanitation led to increased incidences of absenteeism due to disease attacks. This high absenteeism led to low academic performance among learners. Schools with inadequate sanitation amenities also experienced lower enrollment rates compared to schools with adequate sanitation amenities.

\section{RECOMMENDATIONS}

In line with the conclusions, the study made the following recommendations.

i. The school administration should construct more sanitation amenities in their schools to correspond with the high population of children and also cater for learners with physical disabilities.

ii. The Ministry of Education should develop a new construction requirement for early childhood learners' social amenities to ensure that the facilities are appropriate for children aged three to nine years in early childhood and lower primary schools.

iii. Other social amenities such as electricity should be distributed to all buildings in primary schools to make them accessible to all learners.

iv. The Ministry of Education and other education stakeholders should emphasize the role of social amenities in primary schools in order to improve the learners' motivation and overall academic performance.

v. The school administration should ensure they provide diverse social amenities to cater for all learners and to encourage their cognitive and motor development. This could be achieved through maximum utilization of the school compound to cater for diverse disciplines and materials.

The Ministry of Education, Constituency Development Fund and the local community should ensure that all schools had access to piped water to reduce occurrence of diseases such as typhoid, cholera and other highly contagious diseases which affect learners' access to education through high absenteeism rates.

\section{REFERENCES}

Edwards, N. (2006). School Amenities and Student Achievement: Student Perspectives on the Connection between the Urban Learning Environment and Student Motivation and Performance. Unpublished Masters Thesis. Obio State University.

Eshuchi, R. (2013). Promoting Hand-washing with Soap Behaviour in Kenyan Schools: Learning from Puppetry Trials among Primary School Children in Kenya. Unpublished Master's Thesis. Queensland University of Technology. 
Gabbad, A. and Elawad, M. (2014). Environmental Sanitation Factors Associated with Intestinal Parasitic Infections in Primary School Children in Elengaz, Khartoum, Sudan. Journal of Environmental Science, 8(1), 119121. https://doi.org/10.9790/2402-0815119121

Gorman, D. A. (2010). The Effect of Athletic Participation on Academic Achievement for High School Seniors in Eastern Tennessee. Unpublished Doctorate Thesis. Tennessee University.

Guy, H. and Haller, L. (2004). Evaluation of the costs and benefits of water and sanitation improvements of the global level. WHO, Geneva.

Kathuri, J. N. and Pals, D. A. (1983). Introduction to Educational Research. Egerton University: Educational Media Center.

Lawrence, B. M. (2011). Dramatic Play and Social/Emotional Development. Unpublished Maters Thesis. Concordia University Portland.

Maphoso, L. and Mahlo, D. (2014). Basic Amenities and Academic Achievement: A Comparative Study between Boarding and Non-boarding Schools. International Journal of Education and Science, 6(2), 309-315. https:// doi.org/10.1080/09751122.2014.11890142

McMillen, T. (1991). Reversing the Imbalance of Athletics and Academics. The Elementary School Journal, 91(5), 48990. https://doi.org/10.1086/461671

Mbula, S., Mulwa, A. and Kyalo, D. (2014). Access to Improved Sanitation: Implication for Sustainable Implementation of Hygiene Practices Secondary Schools in Machakos County, Kenya. European Scientific Journal, 10(1), 151-168.

Milkie, M. A. and Warner, C. H. (2011). Classroom Learning Environments and the Mental Health of First Grade Children. Journal of Health and Social Behavior, 52(1), 14-22. https:// doi.org/10.1177/0022146510394952

Mugenda, O. M. and Mugenda, A. O. (2003). Research Methods: Qualitative and Quantitative Approaches. Nairobi- Kenya: Africa Centre for Technology Studies (ACTS) Press.

Obure, A. (2009). Scaling School W ASH in Rural Kenya: An Assessment of Kenya Education Sector Support Program. Geneva.

Owoeye, J. and Yara, P. (2011). School Amenities and Academic Achievement of Secondary School Agricultural Science in Ekiti State, Nigeria. Asian Social Science, 7(7), 64-66. https://doi.org/10.5539/ass.v7n7p64

Redhouse, D. (2004). Getting to boiling point: Turning up the heat on Water and Sanitation. National Water Sector Assessments. Water Aid.

\section{APPENDIX I}

School Children Fetching Water from a Nearby Stream

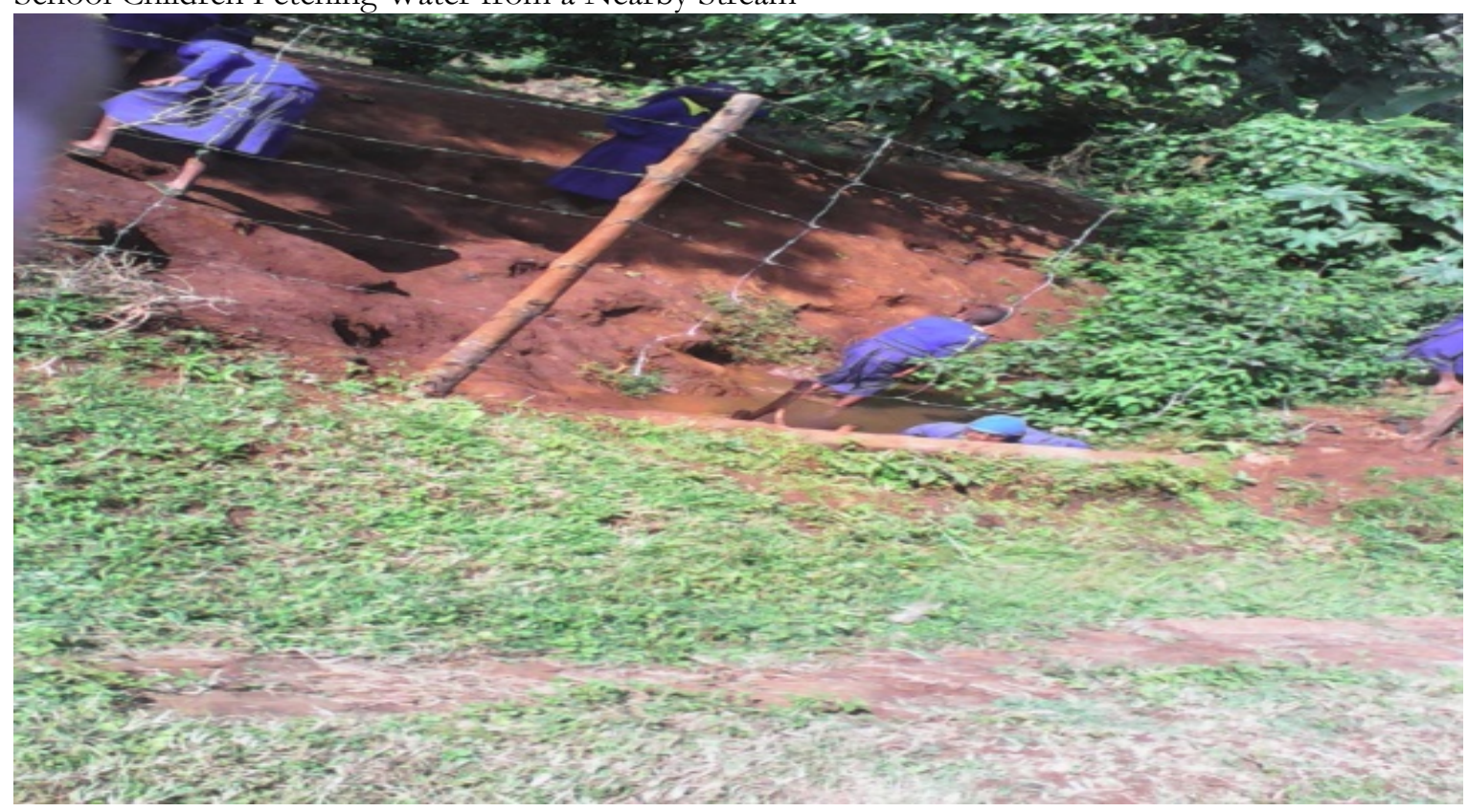

